\title{
The effect of chip former on power loading of re- cessing tool
}

\author{
Jiři Kratochvíl 1,*, Marek Sadílek ${ }^{1}$, Jozef Mrazik ${ }^{2}$ \\ ${ }^{1}$ VSB-TUO, Fakulty of Mechanikal Engieniring 17. listopadu 15/2172, 70833 Ostrava-Poruba, CZ \\ ${ }^{2}$ University of Žilina, Faculty of Mechanical Engineering, Univerzitna 1, 010 26, Žilina, SK
}

\begin{abstract}
The article handles the influence of a chip former on cutting force and its components. This is allowed by using three grooving inserts from ISCAR company, which differ only with the chip former. These inserts have the same base material, coating and they are designed for the same proportion of recessed slot. The conditions of experiment were used in intersection of recommended cutting conditions of the 3 inserts. During the experiment were observed the components of cutting force at changing feed and cutting speed. The results were compiled in tables and graphs were created for each of the used inserts. The particular force loads of the inserts were compared in the end and conclusions thereof were made.
\end{abstract}

Keywords: Recessing, Forces at cutting, Chip formers

\section{Introduction}

The cutting production technologies are still being used in factories, one of them is turning. Turning operation serves for production of rotation parts, where one of the operation sectors is the recessing. This article concludes the comparison of recessing inserts from ISCAR CR s.r.o. company. These inserts have the same base material, coating and they are designed for the same proportion of recessed slot. The comparison was done based on force loading at the defined recess.

\section{Experiment conditions}

For introducing the experiment it is necessary to get familiar with entry conditions, which can influence the experiment. For this experiment were used the following conditions:

- Machine - DMG MoriSeiki NLX 2500/700.

- Dynamometr Kistler 9129AA.

- Material at experiment 1.6722 - 16NiCrMo16-5.

- Tool - Turning recession cutter MAHR 25 with adapter HGPAD 4R-T12 and insert type DGN 4003J, DGN 4003C a GRIP 4004Y.

\footnotetext{
* Corresponding author: Jiri.kratochvil@vsb.cz

Reviewers: Peter Demeč, Anna Rudawska
} 


\subsection{Material}

For this experiment material 1.6722 - 16NiCrMo16-5 was chosen. Rounded bar with diameter $150 \mathrm{~mm}$ and length $250 \mathrm{~mm}$ was used.

It concerns alloy cast construction steel with significantly high yield strength and tensile strength. Among further characteristics of the material belong sufficient moulding capacity and tenacity [1]. Numeric expression of mechanical features is resumed in Table 1.

Table 1. Mechanical properties [1]

\begin{tabular}{|c|c|c|}
\hline Tensile strength Rm (MPa) & Yield strength Re (MPa) & Elongation A (\%) \\
\hline 1450 & 1150 & 12 \\
\hline
\end{tabular}

Chemical composition of the steel can be seen in Table 2 .

Table 2. Chemical composition (Weight \%) [1]

\begin{tabular}{|c|c|c|c|c|c|c|c|}
\hline $\mathbf{C ~ ( \% ) ~}$ & $\mathbf{S i}$ (\%) & Mn (\%) & P (\%) & S (\%) & Cr (\%) & Ni (\%) & Mo (\%) \\
\hline $0.12-0.18$ & $\leq 0.50$ & $\leq 0.50$ & $\leq 0.030$ & $\leq 0.025$ & $1.00-1.40$ & $4.00-4.50$ & $0.15-0.45$ \\
\hline
\end{tabular}

Typical application of alloy structural steels is in the field of ship, vehicle, airplane, guided missile, weapons, railway, bridges, pressure vessel, machine tools, mechanical components with a bigger sectional size and so on.

\subsection{Tool}

The turning recessing tool MAHR 25 (Fig. 1.a) with adapter HGPAD 4R-T12 (Fig. 1.b) was chosen for the experiment.

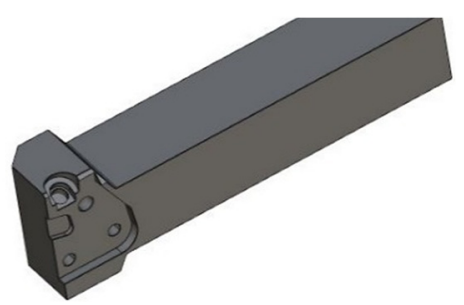

a)

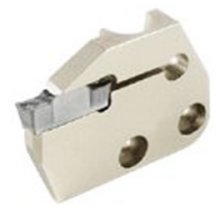

b)

Fig. 1. a) Turning recessing tool MAHR 25 [2], b) Adapter HGPAD 4R-T12 [2]

The adapter is provided with inserts. During the experiment were used 3 types of inserts, the inserts type DGN 4003J, DGN 4003C and GRIP 4004Y (Fig. 2). Particular dimensions and recommended cutting conditions were summarized in Table 3. All compared inserts had the same base material IC 808 and the same coating TiAlN/AlTiN+TiN applied by PVD method [2-4].

Table 3. Dimensions and recommended cutting conditions of the inserts [2]

\begin{tabular}{|c|c|c|c|c|c|c|c|c|}
\hline \multirow{2}{*}{ Fig. 2 } & \multirow{2}{*}{ Typ } & CW & RE & INSL & $\boldsymbol{f}_{\boldsymbol{z} \min }$ & $\boldsymbol{f}_{\boldsymbol{z} \max }$ & $\boldsymbol{v}_{\boldsymbol{c} \min }$ & $\boldsymbol{v}_{\boldsymbol{c} \max }$ \\
\cline { 3 - 9 } & & $\mathrm{mm}$ & $\mathrm{mm}$ & $\mathrm{mm}$ & $\mathrm{mm}$ & $\mathrm{mm}$ & $\mathrm{m} \cdot \mathrm{min}^{-1}$ & $\mathrm{~m} \cdot \mathrm{min}^{-1}$ \\
\hline b) & DGN 4003J & 4 & 0.3 & 18.9 & 0.05 & 0.18 & 80 & 180 \\
\hline c) & DGN 4003C & 4 & 0.3 & 18.8 & 0.1 & 0.3 & 80 & 180 \\
\hline d) & GRIP 4004Y & 4 & 0.4 & 19 & 0.09 & 0.24 & 80 & 180 \\
\hline
\end{tabular}




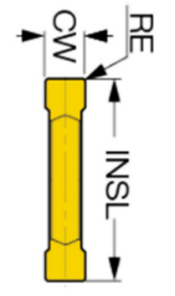

a)

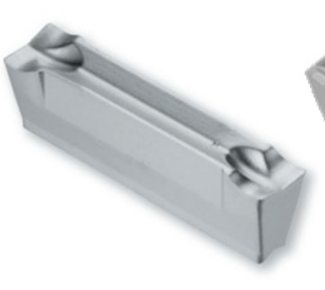

b)

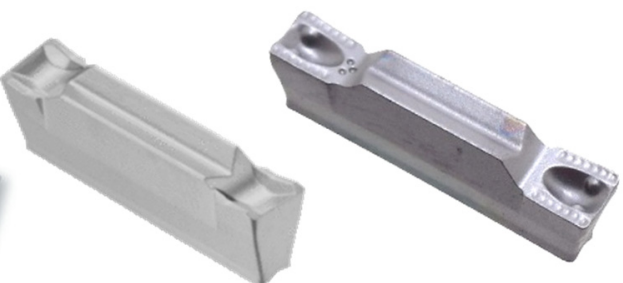

c) d)

Fig. 2. a) Scheme with dimensions, Picture of insert type: b) DGN 4003J, c) DGN 4003C, d) GRIP 4004Y [2]

\subsection{Selection of cutting conditions}

Within parameter selection there were three cutting speeds chosen, minimum $v_{c l}=80$ m.min ${ }^{-1}$, maximum $v_{c 3}=180 \mathrm{~m} \cdot \mathrm{min}^{-1}$ and medium value $v_{c 2}=130 \mathrm{~m} \cdot \mathrm{min}^{-1}$ of the speed. At feed step selection three different feeds were chosen, which approximately come out of intersection of feeds recommended by producer. From this intersection was again selected minimum $f_{1}=0.1 \mathrm{~mm}$, maximum $f_{3}=0.2 \mathrm{~mm}$ and medium value $f_{2}=0.15 \mathrm{~mm}$ of the feed.

\section{Course of experiment}

During the experiment all three values of feed were used for each value of the selected cutting speed.

For each combination of cutting conditions there were 3 recessing of width $4 \mathrm{~mm}$ and depth $2 \mathrm{~mm}$ turned, always with the new cutting edge for avoidance of results interference by wearing off the tool. Between particular recessing were gaps $2 \mathrm{~mm}$.

When turning the recessing the components of cutting force were measured with usage of dynamometer Kistler 9129AA [5-7]. The minimum, maximum and medium values of individual cutting force components were evaluated at each recessing, with help of DynoWare program provided with dynamometer (the range of evaluated data was determined by two vertical lines, which is visible on Fig. 3. For further processing the average value of particular cutting force components at each recessing was figured. As there were three recessing turned for each combination of cutting conditions, it was necessary to eventually calculate the average of values from the three recessing. The passive component of cutting force proved as minimal during the measurement and therefore it was excluded for further processing, see Fig. 3.

In Fig. 3 it is possible to see the progress of force components for the set of three recessing, where green colour marks the cutting component of force $F_{c}$, blue colour means feed component of force $F_{f}$ and black is passive component of force $F_{p}$. By means of the formula (1) was then calculated the final cutting force $F$.

$$
F=\sqrt{F_{c}^{2}+F_{f}^{2}}
$$

$F$ - final cutting force (N),

$F_{c}$ - cutting component of force $(\mathrm{N})$,

$F_{f}$ - feed step component of force $(\mathrm{N})$. 


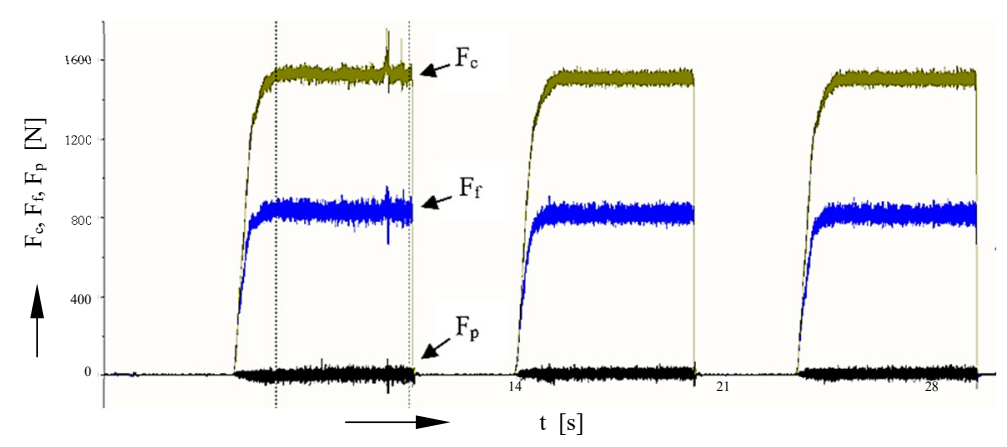

Fig. 3. Example of measured data record (DGN 4003J, $v_{c}=130 \mathrm{~m} \cdot \mathrm{min}^{-1}, f=0.15 \mathrm{~mm}$ )

\section{Evaluation of experiment}

In this chapter can be found the factual measured and calculated values matching with the particular cutting conditions for single inserts.

\subsection{Insert DGN 4003J}

This insert is the first choice for soft material, parting the tubes, small diameters and thinwalled parts. It is generally applied on low carbon, alloy and austenitic stainless steel by using low-to-medium feeds [2].

The values measured for insert DGN 4003J are compiled in the Table 4. From the calculated average values was subsequently created a diagram of dependency of particular components and total cutting force on the used cutting conditions (Fig. 4).

Table 4. Measured and calculated values of individual cutting force components for insert DGN 4003J

\begin{tabular}{|c|c|c|c|c|c|c|c|c|c|c|}
\hline $\boldsymbol{v}_{\boldsymbol{c}}$ & $\boldsymbol{f}$ & $\boldsymbol{F}_{\boldsymbol{f} 1}$ & $\boldsymbol{F}_{\boldsymbol{f} 2}$ & $\boldsymbol{F}_{\boldsymbol{f} \mathbf{3}}$ & $\boldsymbol{F}_{\boldsymbol{c} \boldsymbol{1}}$ & $\boldsymbol{F}_{\boldsymbol{c} \boldsymbol{2}}$ & $\boldsymbol{F}_{\boldsymbol{c} 3}$ & $\boldsymbol{F}_{\boldsymbol{f}}$ & $\boldsymbol{F}_{\boldsymbol{c}}$ & $\boldsymbol{F}$ \\
\hline${\mathrm{m} . \mathrm{min}^{-1}}^{\mathrm{m} m}$ & $\mathrm{~N}$ & $\mathrm{~N}$ & $\mathrm{~N}$ & $\mathrm{~N}$ & $\mathrm{~N}$ & $\mathrm{~N}$ & $\mathrm{~N}$ & $\mathrm{~N}$ & $\mathrm{~N}$ \\
\hline $\mathbf{8 0}$ & $\mathbf{0 . 1}$ & 858.3 & 895.7 & 890.7 & 1292 & 1322 & 1316 & 882 & 1310 & $\mathbf{1 5 7 9}$ \\
\hline $\mathbf{8 0}$ & $\mathbf{0 . 1 5}$ & 1015 & 1007 & 1018 & 1683 & 1662 & 1667 & 1013 & 1671 & $\mathbf{1 9 5 4}$ \\
\hline $\mathbf{8 0}$ & $\mathbf{0 . 2}$ & 1093 & 1092 & 1097 & 1845 & 1850 & 1852 & 1094 & 1849 & $\mathbf{2 1 4 8}$ \\
\hline $\mathbf{1 3 0}$ & $\mathbf{0 . 1}$ & 742 & 734 & 731 & 1148 & 1141 & 1139 & 736 & 1143 & $\mathbf{1 3 5 9}$ \\
\hline $\mathbf{1 3 0}$ & $\mathbf{0 . 1 5}$ & 835 & 820 & 818 & 1533 & 1511 & 1508 & 824 & 1517 & $\mathbf{1 7 2 7}$ \\
\hline $\mathbf{1 3 0}$ & $\mathbf{0 . 2}$ & 905 & 903 & 900 & 1881 & 1871 & 1866 & 903 & 1873 & $\mathbf{2 0 7 9}$ \\
\hline $\mathbf{1 8 0}$ & $\mathbf{0 . 1}$ & 632 & 629 & 627 & 1068 & 1064 & 1060 & 629 & 1064 & $\mathbf{1 2 3 6}$ \\
\hline $\mathbf{1 8 0}$ & $\mathbf{0 . 1 5}$ & 758 & 758 & 755 & 1445 & 1445 & 1441 & 757 & 1444 & $\mathbf{1 6 3 0}$ \\
\hline $\mathbf{1 8 0}$ & $\mathbf{0 . 2}$ & 851 & 838 & 837 & 1815 & 1795 & 1795 & 842 & 1802 & $\mathbf{1 9 8 9}$ \\
\hline
\end{tabular}

In the diagram (Fig. 4) is apparent a huge increase of force components with the increasing feed, especially the cutting component of cutting force. With the increasing cutting speed however both followed cutting force components slightly drop down. 


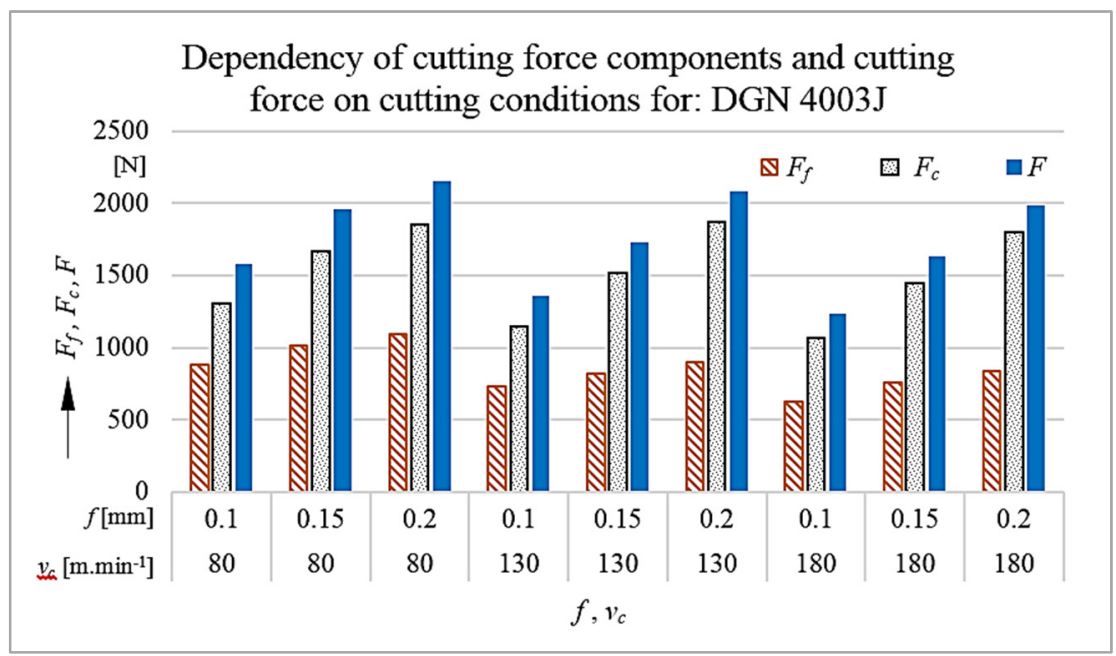

Fig. 4. Dependency of cutting force components and cutting force on cutting conditions for: DGN 4003J

\subsection{Insert DGN 4003C}

This insert is widely used for grooving and parting bars, hard materials and tough applications. A positive rake and single cavity with a negative land and shoulders make the cutting edge extremely resistant. The insert is designed for medium-to-high feed.

The measured and calculated values of individual cutting force components for insert DGN 4003C are displayed in Table 5 and in graphical view in Fig. 5.

Table 5. Measured and calculated values of individual cutting force components for insert DGN 4003C

\begin{tabular}{|c|c|c|c|c|c|c|c|c|c|c|}
\hline $\boldsymbol{v}_{\boldsymbol{c}}$ & $\boldsymbol{f}$ & $\boldsymbol{F}_{\boldsymbol{f} 1}$ & $\boldsymbol{F}_{\boldsymbol{f} \boldsymbol{2}}$ & $\boldsymbol{F}_{\boldsymbol{f}}$ & $\boldsymbol{F}_{\boldsymbol{c} \boldsymbol{1}}$ & $\boldsymbol{F}_{\boldsymbol{c} \boldsymbol{2}}$ & $\boldsymbol{F}_{\boldsymbol{c} 3}$ & $\boldsymbol{F}_{\boldsymbol{f}}$ & $\boldsymbol{F}_{\boldsymbol{c}}$ & $\boldsymbol{F}$ \\
\hline $\mathrm{m.min}^{-1}$ & $\mathrm{~mm}$ & $\mathrm{~N}$ & $\mathrm{~N}$ & $\mathrm{~N}$ & $\mathrm{~N}$ & $\mathrm{~N}$ & $\mathrm{~N}$ & $\mathrm{~N}$ & $\mathrm{~N}$ & $\mathrm{~N}$ \\
\hline $\mathbf{8 0}$ & $\mathbf{0 . 1}$ & 859 & 851 & 848 & 1243 & 1234 & 1231 & 853 & 1236 & $\mathbf{1 5 0 2}$ \\
\hline $\mathbf{8 0}$ & $\mathbf{0 . 1 5}$ & 970 & 955 & 954 & 1597 & 1582 & 1576 & 960 & 1585 & $\mathbf{1 8 5 3}$ \\
\hline $\mathbf{8 0}$ & $\mathbf{0 . 2}$ & 1071 & 1065 & 1063 & 1886 & 1889 & 1892 & 1066 & 1889 & $\mathbf{2 1 6 9}$ \\
\hline $\mathbf{1 3 0}$ & $\mathbf{0 . 1}$ & 807 & 809 & 808 & 1154 & 1150 & 1147 & 808 & 1150 & $\mathbf{1 4 0 6}$ \\
\hline $\mathbf{1 3 0}$ & $\mathbf{0 . 1 5}$ & 874 & 869 & 868 & 1478 & 1470 & 1469 & 870 & 1472 & $\mathbf{1 7 1 0}$ \\
\hline $\mathbf{1 3 0}$ & $\mathbf{0 . 2}$ & 999 & 994 & 990 & 1817 & 1809 & 1804 & 994 & 1810 & $\mathbf{2 0 6 5}$ \\
\hline $\mathbf{1 8 0}$ & $\mathbf{0 . 1}$ & 762 & 775 & 771 & 1085 & 1086 & 1081 & 769 & 1084 & $\mathbf{1 3 2 9}$ \\
\hline $\mathbf{1 8 0}$ & $\mathbf{0 . 1 5}$ & 909 & 910 & 926 & 1439 & 1434 & 1441 & 915 & 1438 & $\mathbf{1 7 0 4}$ \\
\hline $\mathbf{1 8 0}$ & $\mathbf{0 . 2}$ & 992 & 1012 & 1007 & 1762 & 1767 & 1762 & 1004 & 1764 & $\mathbf{2 0 2 9}$ \\
\hline
\end{tabular}

For Graphical view in Fig. 5. were used the average values of particular cutting force components and cutting force calculated (see formula 1) out of data measured during cutting with insert DGN 4003C. 


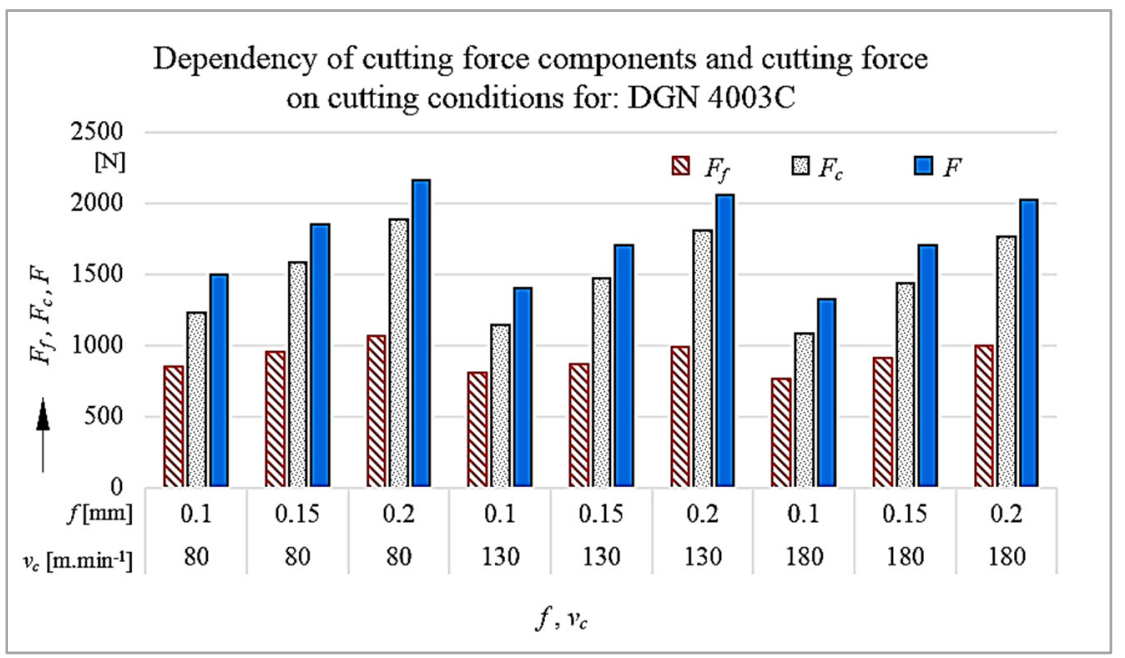

Fig. 5. Dependency of cutting force components and cutting force on cutting conditions for: DGN 4003C

From the graphical view we can observe the significant growth of cutting component of cutting force with the increasing feed and moderate growth of cutting force feed component. On the other hand, the higher cutting speed leads to a slight drop down in cutting component of the cutting force and also to decrease of the total cutting force. The influence of higher cutting speed on feed component is rather small (minor decrease of values).

\subsection{Insert GRIP 4004Y}

Thanks to its curving construction are the inserts GRIP 4004Y the only two-sided inserts on market, which can groove in bigger depth than is their own length [2].

The results of measurements and calculated values for the insert can be found in Table 6 and graphically displayed in Fig. 6.

Table 6. Measured and calculated values of individual cutting force components for insert GRIP 4004Y

\begin{tabular}{|c|c|c|c|c|c|c|c|c|c|c|}
\hline $\boldsymbol{v}_{\boldsymbol{c}}$ & $\boldsymbol{f}$ & $\boldsymbol{F}_{\boldsymbol{f} 1}$ & $\boldsymbol{F}_{\boldsymbol{f} 2}$ & $\boldsymbol{F}_{\boldsymbol{f}}$ & $\boldsymbol{F}_{\boldsymbol{c} 1}$ & $\boldsymbol{F}_{\boldsymbol{c} 2}$ & $\boldsymbol{F}_{\boldsymbol{c} 3}$ & $\boldsymbol{F}_{\boldsymbol{f}}$ & $\boldsymbol{F}_{\boldsymbol{c}}$ & $\boldsymbol{F}$ \\
\hline $\mathrm{m.min}^{-1}$ & $\mathrm{~mm}$ & $\mathrm{~N}$ & $\mathrm{~N}$ & $\mathrm{~N}$ & $\mathrm{~N}$ & $\mathrm{~N}$ & $\mathrm{~N}$ & $\mathrm{~N}$ & $\mathrm{~N}$ & $\mathrm{~N}$ \\
\hline $\mathbf{8 0}$ & $\mathbf{0 . 1}$ & 695 & 694 & 694 & 1181 & 1176 & 1174 & 694 & 1177 & $\mathbf{1 3 6 7}$ \\
\hline $\mathbf{8 0}$ & $\mathbf{0 . 1 5}$ & 854 & 855 & 856 & 1567 & 1562 & 1561 & 855 & 1563 & $\mathbf{1 7 8 2}$ \\
\hline $\mathbf{8 0}$ & $\mathbf{0 . 2}$ & 1013 & 1001 & 996 & 1881 & 1889 & 1890 & 1003 & 1887 & $\mathbf{2 1 3 7}$ \\
\hline $\mathbf{1 3 0}$ & $\mathbf{0 . 1}$ & 667 & 668 & 672 & 1099 & 1097 & 1095 & 669 & 1097 & $\mathbf{1 2 8 5}$ \\
\hline $\mathbf{1 3 0}$ & $\mathbf{0 . 1 5}$ & 796 & 805 & 812 & 1473 & 1464 & 1466 & 804 & 1468 & $\mathbf{1 6 7 4}$ \\
\hline $\mathbf{1 3 0}$ & $\mathbf{0 . 2}$ & 922 & 933 & 934 & 1831 & 1827 & 1822 & 930 & 1827 & $\mathbf{2 0 5 0}$ \\
\hline $\mathbf{1 8 0}$ & $\mathbf{0 . 1}$ & 668 & 689 & 706 & 1055 & 1060 & 1066 & 688 & 1060 & $\mathbf{1 2 6 4}$ \\
\hline $\mathbf{1 8 0}$ & $\mathbf{0 . 1 5}$ & 846 & 885 & 893 & 1442 & 1448 & 1447 & 875 & 1446 & $\mathbf{1 6 9 0}$ \\
\hline $\mathbf{1 8 0}$ & $\mathbf{0 . 2}$ & 922 & 931 & 937 & 1786 & 1789 & 1795 & 930 & 1790 & $\mathbf{2 0 1 7}$ \\
\hline
\end{tabular}

For graphical view in Fig. 6. were used the average values of single cutting force components and cutting force (see Formula 1) calculated out of data measured in cutting with insert GRIP 4004Y. 


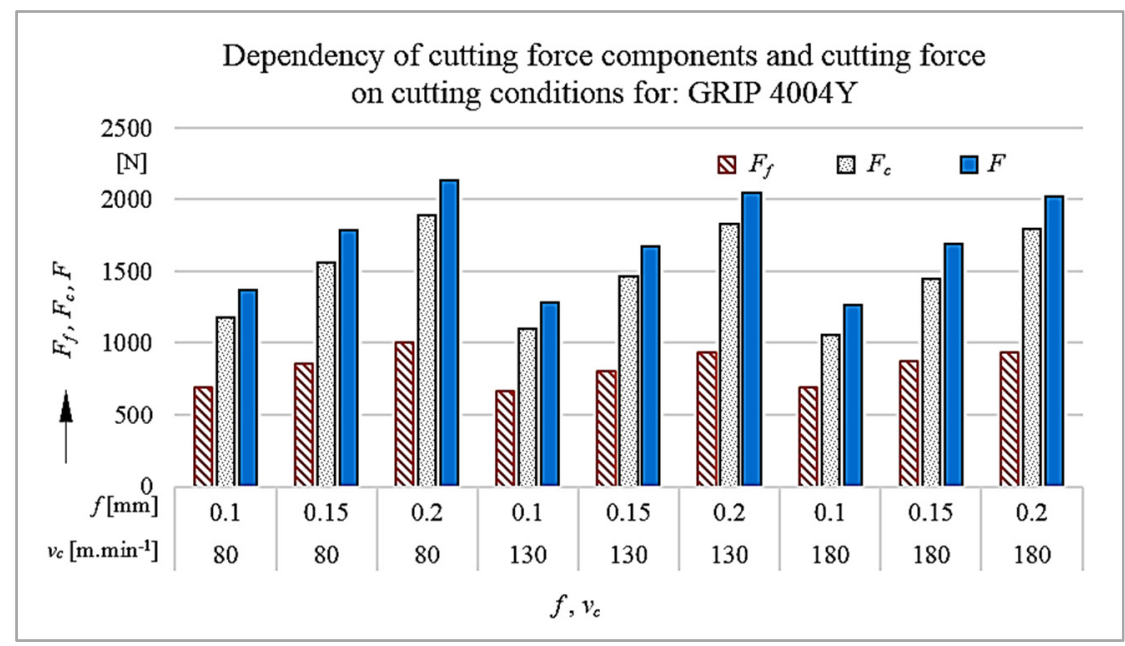

Fig. 6. Dependency of cutting force components and total cutting force on cutting conditions for: GRIP 4004Y

Similar to the previous insert the main portion of effect on the force components increase takes the feed. Raising the cutting speed has slightly decreasing effect on cutting force components and the total cutting force itself.

\section{Comparison of force load of inserts chip formers}

With regards to the previously proved higher effect of feed step on the proportion of cutting force component the values of cutting force were lined ukrap in order to let the feed dependencies show up.

\subsection{Comparison of cutting component of force}

Thanks to the graphical view of the calculated data in Fig. 7 it is evident that the insert type DGN 4003J shows higher force load at most of the tests. For lower cutting speeds and lower feed the insert type GRIP 4004Y has smaller force load. However the differences of cutting component between particular inserts are minor.

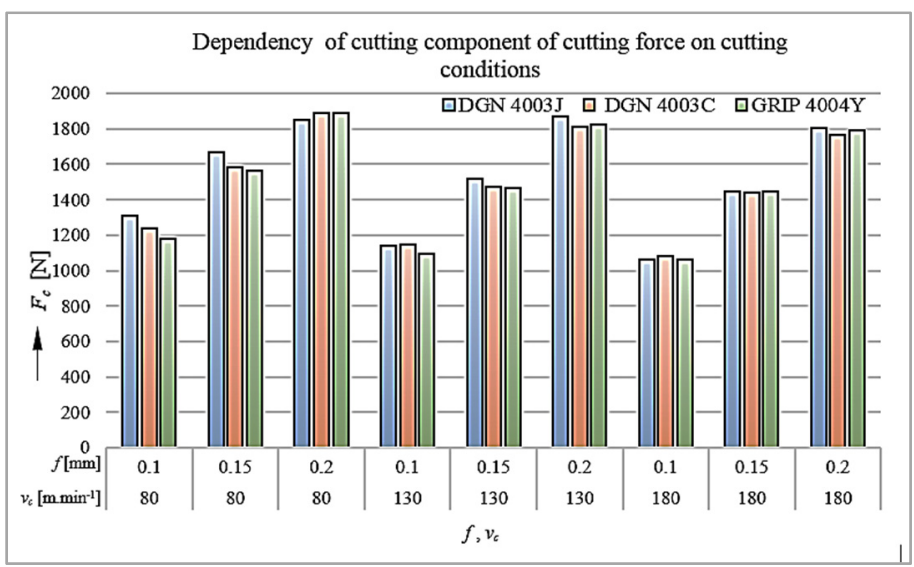

Fig. 7. Dependency of cutting component of force on cutting conditions 
At closer look on the insert type DGN 4003J, see Fig. 2.b is visible sharper cutting edge compared to the other two insert types, which are equipped with facetas on the main and side edge. Despite of its geometry this insert has the highest cutting component of the cutting force in almost all cases.

\subsection{Comparison of feed component of force}

To enable the comparison of feed component of cutting force for the individual applied inserts was created the Fig. 8.

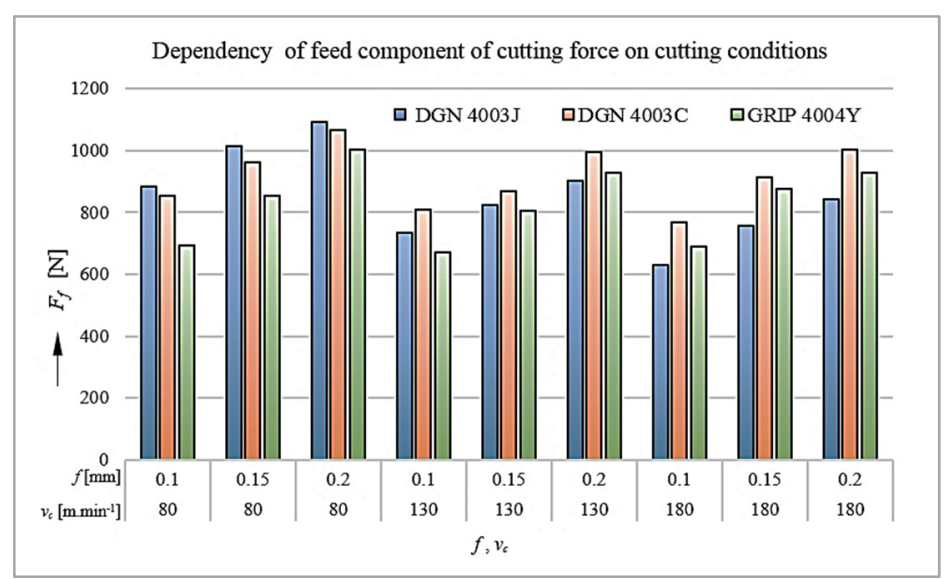

Fig. 8. Dependency of feed component of cutting force on cutting conditions

The biggest differences between individual inserts and their chip formers are visible on Fig. 8. For feed component of cutting force and for higher cutting speed the highest force load shows at insert type DGN 4003C. The lowest force load at the highest cutting force has in this context the insert DGN 4003J. On the other hand the insert GRIP 4004Y has the lowest force load in lower cutting speeds.

\subsection{Comparison of total force}

If the final cutting force is calculated from the recorded values according to formula (1), the result will be dependency of this force on cutting conditions (Fig. 9). At cutting speed $v_{c}=$ $80 \mathrm{~m} . \mathrm{min}^{-1}$ were recognized the biggest differences between the followed inserts. The differences were however lower with higher feed. The lowest force load was measured on insert type GRIP 4004Y.

Also with cutting speed $v_{c}=130 \mathrm{~m} \cdot \mathrm{min}^{-1}$.the lowest force load was detected on insert type GRIP 4004Y in the whole range of applied feeds. The force load of individual inserts was however lower than with cutting speed $v_{c}=80 \mathrm{~m} \cdot \mathrm{min}^{-1}$.

The lowest values of cutting force were reached at cutting speed $v_{c}=180 \mathrm{~m} . \mathrm{min}^{-1}$.. At this cutting speed the lowest force load was achieved with insert DGN 4003J. Though the differences in force load among the followed inserts are the smallest.

It comes out of the graph that for lower cutting speeds and with regards to the final force load is more feasible the insert GRIP 4004Y, while for higher cutting speed it is the insert DGN 4003J. However the difference in force load with insert type GRIP 4004Y is not significant. 


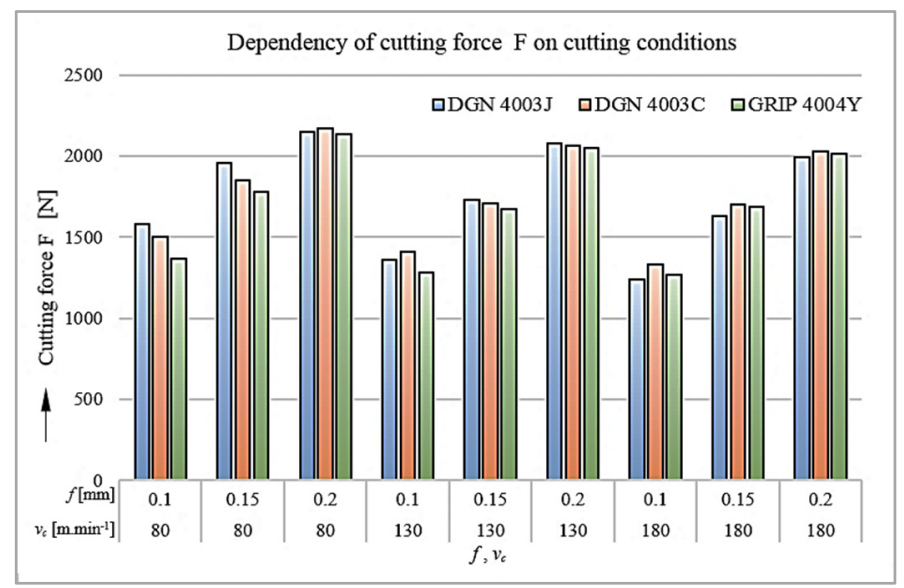

Fig.9. Dependency of force of cutting F on cutting conditions

The drop down at higher cutting speeds can be explained by the chip forming processes, which was well summarized by T. Skopeček [8] including the examples confirming this fact. To get closer understanding this is possible only for plastic materials, in which thermal softening processes apply. The increase in cutting speed leads to higher temperature at the point of cut and to bigger material softening compared to lower speeds. Thanks to this material softening it is not necessary to use such high shearing force to cut off the chip. For confirmation and evaluation of the theory about thermal softening process it would be suitable to install pyrometer or thermal imager e.g. according to the drawing in the article $[9,10]$.

\section{Conclusions}

For comparison of inserts chip formers there were confronted three inserts at differing cutting conditions formed by intersection of producer recommended cutting conditions. From the diagrams created with measured and calculated values comes out the finding that feed influences the force load of insert more than cutting speed does. For lower cutting speeds is more suitable the insert type GRIP 4004Y, which with regards to the minor force differences at higher speeds appear to be the most universal one and therefore also the chip former on this insert is the best constructed for material 1.6722 .

For practical use we can make the conclusion that with the lowest force load it should get to the lowest abrasive wear-out and thus to the highest durability of the machined tool. Research in this field is interesting both to producers of the tools and the companies, which are using this technology and this material, which means mostly companies operating in automotive and aerospace industry.

Article has been done in connection with projects Education system for personal resource of development and research in field of modern trend of surface engineering - surface integrity, reg. no. CZ.1.07/2.3.00/20.0037 financed by Structural Founds of Europe Union and from the means of state budget of the Czech Republic and by project Students Grant Competition SP2018/150 and SP2018/136 financed by the Ministry of Education, Youth and Sports and Faculty of Mechanical Engineering VŠBTUO. 


\section{References}

1. Technical specifications $1.6722 \quad / 16 \mathrm{NiCrMo16-5}$ [online]. http://www.ccsteels. com/Structural_steel/2593.html

2. Iscar.com. Iscareletroniccatalog [online]. https://www.iscar.com/eCatalog

3. J. Novotný, J. Cais, N. Náprstková, Analysis of aluminium alloys AlSi7Mg0.3 and AlMg3 by means of X-Ray Diffraction, In Manufacturing Technology, Vol. 14, 392-397 (2014)

4. S. Kuśmierczak, Methods of evaluation degraded parts. 14th International Scientific Conference Engineering for Rural Development 790-794 (2015)

5. A. Gorog, D. Stančeková, M. Kapustova, I. Gorogova, I., Miturska, Influence of selected cutting conditions on cutting forces. In. Advances in Science and Technology Research Journal, 11, 179 - 185 (2017)

6. D. Stančeková, M. Šajgalík, J. Petru, N. Náprstková, P. Balaz, Implementation of coating for failure elimination of dial gauges. In: METAL 2015. (2015)

7. D. Kalincová, M. Ťavodová, H. Čierna, P.Beňo, Analysis the causes of distortion castings after heat treatment, Acta Metallurgica Slovaca, 23, 182-192 (2017)

8. T. Skopeček, Vliv vybraných parametrů procesu na řezné síly při HSC. In: MM PRŮMYSLOVÉ SPETRUM https://www.mmspektrum.com/clanek/vlivvybranych-parametru-procesu-na-rezne-sily-pri-hsc.html

9. N. Čuboňová, M. Císar, Design of Camera Mount and its Application for Monitoring Machining Process. In: Advances In Science And Technology-Research Journal, 9, 26 (2015)

10. J. Jerzy, I. Kuric, S. Grozav, V. Ceclan, Calibration of 5 axis CNC machine tool with $3 D$ quickSET measurement system. Academic Journal of Manufacturing Engineering Vol. 12, 20-25, (2014)

11. M. Sapieta, A. Sapietová, V. Dekýš, Comparison of the thermoelastic phenomenon expressions, in stainless steels during cyclic loading. Metalurgija. 56, 203-206 (2017) 